\title{
Commentary: Improved Malaria Case Management in Formal Private Sector Through Public Private Partnership in Ethiopia: Retrospective Descriptive Study
}

\author{
Mesele Damte Argaw ${ }^{1,2 *}$, Thandisizwe Redford Mavundla' ${ }^{2}$, Binyam Fekadu Desta ${ }^{1,2}$, Wondwosen Shiferaw \\ Abera', Kassa Daka Gidebo ${ }^{3}$, Temesgen Ayehu Bele ${ }^{4}$, Dereje Dillu ${ }^{4}$ \\ 'USAID Transform: Primary Health Care, JSI Research \& Training Institute, Inc., Addis Ababa, Ethiopia \\ ${ }^{2}$ University of South Africa, Department of Health Studies, Pretoria, South Africa \\ ${ }^{3}$ Welaita Sodo University, School of Public Health, College of Health Sciences and Medicine, Wolaita Sodo, Ethiopia \\ ${ }^{4}$ Federal Ministry of Health, Addis Ababa, Ethiopia
}

Article Info

\section{Article Notes}

Received: August 17, 2018

Accepted: September 5, 2018

\section{*Correspondence}

Mesele Damte Argaw, USAID Transform: Primary Health Care, Ethiopia

JSI Research \& Training Institute, Inc., P.O. Box 1392 code 1110, Addis Ababa, Ethiopia; Email: mdamte5@gmail.com

${ }^{\circ} 2018$ Argaw MD. This article is distributed under the terms of the Creative Commons Attribution 4.0 International License.

Original Article Citation: "Improved malaria case management in formal private sector through public private partnership in Ethiopia: retrospective descriptive study", by Mesele D. Argaw, Asfawesen GY. Woldegiorgis, Derebe T. Abate and Mesfin E. Abebe (2016). Malaria Journal 15:352 DOI 10.1186/ s12936-016-1402-7

\section{Keywords}

Malaria

Public-Private Mix

Adherence to standards

Elimination
Malaria is a major public health problem and has globally caused 445,000 deaths in the year 2016. In addition, during the same reporting period, an estimated 216 million cases of malaria occurred worldwide (95\% confidence interval [CI]: 196-263 million) ${ }^{1}$.

Argaw et al. (2016) in their retrospective descriptive study, published in 'Malaria Journal' presented the four-year (20122015) achievements in 110 public-private mix (PPM) malaria care facilities located in five regional states and one city administration in Ethiopia ${ }^{2}$. The authors explored how the stepwise intervention benefited over 873,707 malaria-suspected patients. Out of these, one fourth $(25.6 \%)$, were diagnosed and treated for malaria infections. The program demonstrated significant improvements in shifting from presumed diagnosis to parasitological confirmation of malaria-suspected patients before resuming their treatments. In addition, adherence of private health sector providers to appropriate species-specific treatment was significantly improved from $47 \%$ to 98\% in 2012 and 2015, respectively. Hence, scale-up of the tested approach was recommended, i.e. the formal public-private mix for malaria care services by the government and development partners ${ }^{2}$. Nevertheless, it is important to highlight that the high rate of adherence to the national diagnosis and treatment standards and registered performance improvements are likely to be set back if there is an interruption of basic anti-malaria supplies and a lack of consistent and reliable partnership with public sector ${ }^{3-5}$.

To highlight the importance of providing continuous supportive supervision, and engaging the private providers, we searched and reviewed relevant gray and published literature ${ }^{6-8}$. The result of these studies confers that most malaria programs lack understanding of the composition and contribution of the private health sector in malaria diagnosis and treatment.

After an evaluation of uncomplicated malaria case management at the outpatient facilities of the private sector in West Gojjam zone of the Amhara region, it was revealed that private providers' adherence to the national malaria diagnosis and treatment standards was poor. Some patients were over treated with antimalarial medication and broad-spectrum antibiotics like Tetracycline, Metronidazole, and Clarithromycin. Other patients were treated against the global 


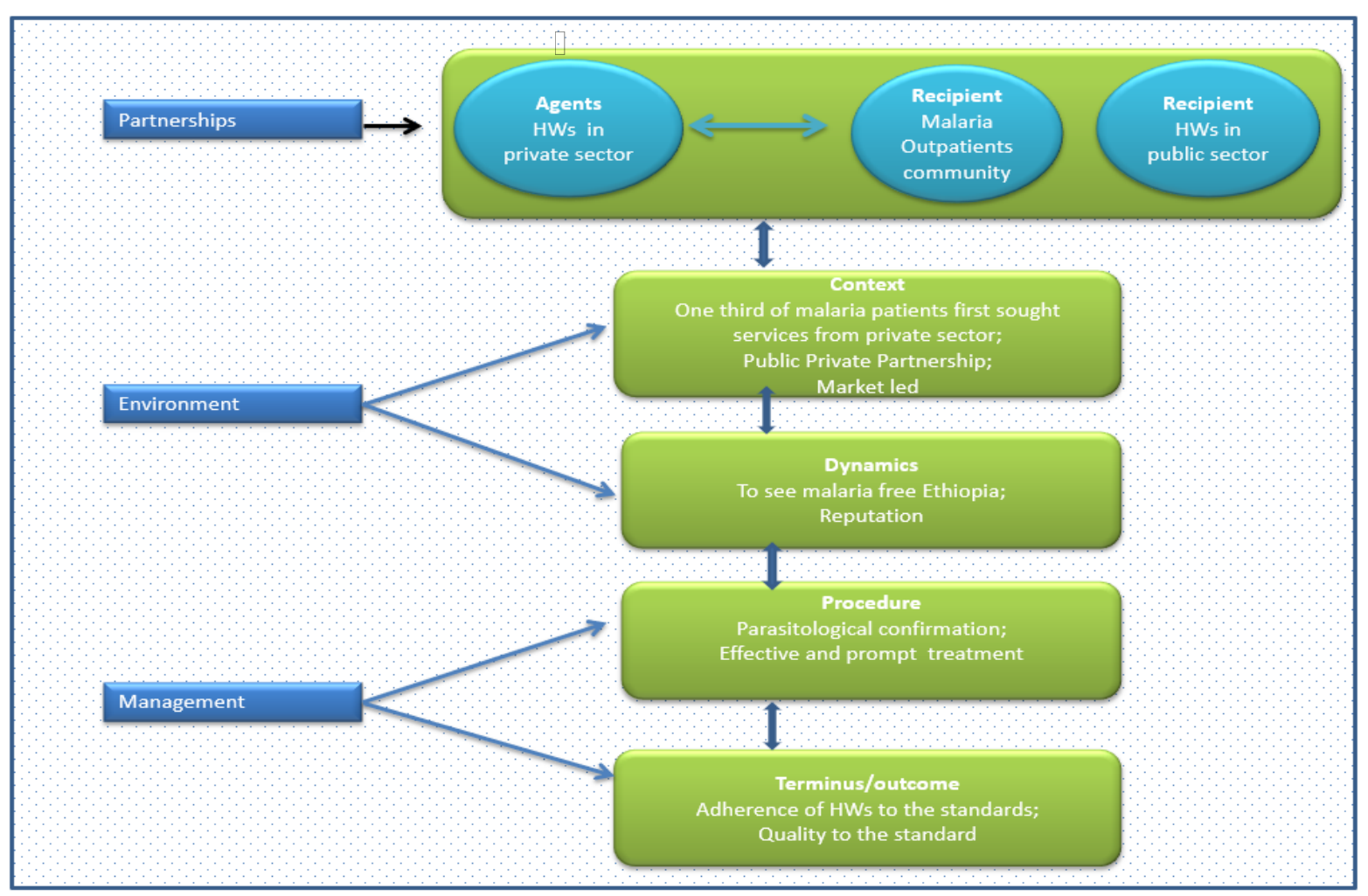

Figure 1: Conceptual framework on survey lists adopted to support public-private Partnership ${ }^{17}$

and national recommendations using monotherapies (i.e. Arthem or Artesunate injections). Moreover, the quality of services was compromised due to health providers' preferences of one anti-malaria drug over the another, and injectables over tablets ${ }^{4,5}$.

Despite this, there is evidence of successful, costeffective, affordable, equitable, quality assured, and accessible health program services in Ethiopia-12. In addition, there are several global experiences indicating that public-private partnership is a widely acknowledged approach for the health sector to tap into and for the optimal use of available resources for health which include: Finance, Infrastructure, Human Resources, Pharmaceutical products and Health technology etc. ${ }^{13-15}$.

The Federal Ministry of Health has documented the presence of at least three approaches of public-private partnership in the health sector. The approaches in place are social franchising, concessions and joint venture. To confirm the stewardship commitment, the ministry has developed the public-private partnership directives ${ }^{13}$. However, the document lacks details of implementation guidance. Furthermore, according to the malaria strategy plan (2017-2020), the country intends to eliminate malaria, at least from historically low malaria transmission $\operatorname{areas}^{16}$. During the implementation of this strategic plan, collaboration among the public sector, private sector, and the community, for surveillance, standardizing services and prevention and control of counterfeit drug circulation is needed.

Argaw et al. (2016) recommend the scaling-up of public-private mix for malaria care services. However, it was not clearly described through working guidelines ${ }^{2}$. Therefore, we recommend that the public health sector, the private health sector and the community work together towards developing clear working guidelines. The guidelines should be developed based on the components of the survey list of 'The Practice Oriented Theory' by Dickoff, James and Wiedenbach ${ }^{17}$. The components of the survey list as suggested by Dickoff et al. are the agent, the recipient, the context, terminus, dynamics, and procedure. Figure 1 describes the details of the relationships between three major elements; partnership, environment, and management ${ }^{18}$. The agents are the private providers, and the recipients are the community and the public sector. Finally, assigning the roles and responsibilities for all actors is recommended.

\section{Acknowledgements}

MDA BFD and WSA receive salary support from JSI Research and Training Institute Inc. We also thank colleagues who reviewed, proofread the manuscript and provided us with helpful suggestions on the manuscript. 


\section{References}

1. World Health Organization. World malaria report 2017. Geneva: WHO; 2017. From: http://www.who.int/malaria/publications/ world-malaria-report-2017/report/en/

2. Argaw MD, Woldegiorgis AG, Abate DT, et al. Improved malaria case management in formal private sector through public private partnership in Ethiopia: retrospective descriptive study. Malaria Journal. 2016; 15(1): 352.

3. Aguemon B, Damien BG, Hinson AV, et al. Malaria Case-Management in Urban Area: Various Challenges in Public and Private Health Facilities in Benin, West Africa. The Open Public Health Journal. 2018; 11(1): 54-61.

4. Argaw MD, Mavundla TR, Gidebo KD. Management of uncomplicated malaria in private health facilities in north-west Ethiopia: a clinical audit of current practices. 2018. (unpublished)

5. Argaw MD, Mavundla TR, Gidebo KD. Community and Health Care Providers Perception on Quality of Private Sector Outpatient Malaria Care in North West Ethiopia: A Qualitative Study. 2018. (unpublished)

6. Ethiopian Federal Ministry of Health. National malaria guidelines. 3rd edition. Addis Ababa: EFMOH; 2012.

7. Bennett A, Avanceña AL, Wegbreit J, et al. Engaging the private sector in malaria surveillance: a review of strategies and recommendations for elimination settings. Malaria Journal. 2017; 16(1): 252.

8. Chuma J, Okungu V, Molyneux C. Barriers to prompt and effective malaria treatment among the poorest population in Kenya. Malaria Journal. 2010; 9(1): 144 .

9. MoH, HEPCAPS2 Project. Strengthening Public Private Partnerships for More and Better Health Outcomes in Ethiopia: Expert Reviews and Case Studies. Ethiopian Ministry of Health, Harvard T.H. Chan School of Public Health, JSI Research \& Training Institute, Inc.: Addis Ababa, Ethiopia, Boston, Massachusetts; 2015.

10. Yimer YT, Yalew AW. Magnitude and predictors of anti-retroviral treatment (ART) failure in private health facilities in Addis Ababa, Ethiopia. PLoS One. 2015; 10 :e0126026.

11. Rao P, Gabre-Kidan T, Mubangizi DB, et al. Leveraging the private health sector to enhance HIV service delivery in lower-income countries. J Acquir Immune Defic Syndr. 2011; 57: S116-9.

12. World Health Organization. Partnerships for malaria control: engaging the formal and informal private sector. Geneva: World Health Organization; 2006.

13. Ethiopian Federal Ministry of Health. Public private partnership in Health: strategic framework for Ethiopia. Addis Ababa: EFMOH; 2013.

14. Widdus R. Public-private partnerships for health: their main targets, their diversity, and their future directions. Bulletin of the World Health Organization. 2001; 79: 713-20.

15. Bhattacharyya 0 , Khor S, McGahan A, et al. Innovative health service delivery models in low and middle-income countries-what can we learn from the private sector. Health Research Policy and Systems. 2010; 8(1): 24.

16. Ethiopian Federal Ministry of Health. National strategic plan for malaria prevention, control and elimination in Ethiopia 2017- 2020. Addis Ababa: EFMOH; 2017.

17. Dickoff J, James P, Wiedenbach E. 1968. Theory in practice discipline: part I practice-oriented theory. Nursing Researcher. 1968; 17(5): 415 $-434$.

18. Amukugo HJ, Jooste K, Mitonga HK. Development of model to facilitate male involvement in the reproductive health context by the registered nurses. International Journal of Advanced Nursing Studies. 2015; 4(2): 122-130. 